
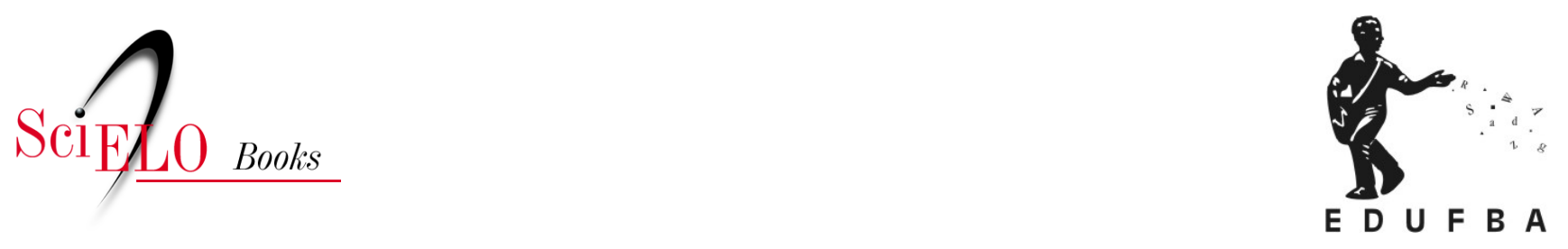

\title{
Inscrição social e novo estatuto social dos pobres
}

\author{
José Carlos da Exaltação Torres
}

\section{SciELO Books / SciELO Livros / SciELO Libros}

TORRES, J.C.E. Inscrição social e novo estatuto social dos pobres. In: Cadastro Único: tecnologia de reclassificação social [online]. Salvador: EDUFBA, 2016, pp. 33-41. ISBN: 978-65-5630-011-5. https://doi.org/10.7476/9786556300115.0004.

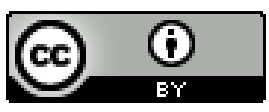

All the contents of this work, except where otherwise noted, is licensed under a Creative Commons Attribution 4.0 International license.

Todo o conteúdo deste trabalho, exceto quando houver ressalva, é publicado sob a licença Creative Commons Atribição 4.0. 


\section{INSCRIÇÃO SOCIAL E NOVO ESTATUTO SOCIAL DOS POBRES}

Na perspectiva aqui adotada, a pobreza dá conta de uma condição ou um estado social atribuído a parcelas da população nas sociedades modernas; uma condição intimamente relacionada à noção de desigualdade, decorrente de um modelo de sociedade forjado em torno das relações de trabalho, elemento central de ordenamento social na modernidade. Assim, a noção de pobreza envolve representações morais e classificações sociais em função de determinados atributos sociais que têm seu reconhecimento dado pelo peso simbólico que esses atributos assumem no conjunto da ordem social. Mas não é um processo que se dá passiva ou naturalmente. Trata-se de uma construção, e reflete ao mesmo tempo uma concepção de realidade social predominante nesse exercício de classificação.

Segundo Bourdieu (2008, p. 444), as classificações sociais dão-se por meio de lutas que transladam toda a sociedade, das práticas cotidianas dos agentes e grupos sociais aos sistemas oficiais de classificação, "o sistema dos esquemas classificatórios constitui-se em sistema de classificação objetivado e institucionalizado". A institucionalização dos esquemas classificatórios institui o poder de classificar, a competência de distinguir, de designar. A classificação torna-se um ato de reconhecimento de existência social, pois "a imposição de um nome reconhecido opera uma verdadeira transmutação da coisa nomeada [...], torna-se uma função social, isto é, um mandato, uma missão”. (BOURDIEU, 2008, p. 444, grifo do autor) A classificação imputa uma condição, determina um lugar. Quando se atribuem determinadas características, simultaneamente negam-se outras. Quando se diz o que é, 
diz-se também o que não é. Quando se estabelece uma classificação em torno de uma característica específica - como, no caso do Brasil, a condição de pobreza por insuficiência de renda, tal qual preconiza o principal critério de elegibilidade dos programas sociais de transferência de renda -, está em jogo uma concepção social e o lugar que os pobres ocupam na concepção e desenho do "Estado social”, especialmente em relação à assistência social. A classificação não é só atribuição de significado, mas um mecanismo social e político que opera processos de inclusão ou exclusão social.

Esse processo é fundamental na construção da realidade, e a realidade não é menos que o mundo que se nos apresenta à frente (e em todos os ângulos) e do qual participamos; não apenas o mundo material, sensível, mas também, e especialmente, o mundo simbólico, que dá conta do significado que as coisas têm para cada um dos viventes, para os diversos grupos e para a coletividade em seu conjunto. As formas de apreender essa realidade estão de tal modo relacionadas às formas de vivê-la e de experimentá-la, condicionadas às formas de distribuição das coisas e das gentes no "espaço social" que a conforma (BOURDIEU, 2008), que dificilmente se pode estabelecer alguma precedência de umas sobre outras. É o processo e a natureza da socialização de todo indivíduo que lhe permite construir mecanismos de apreensão do mundo, e, em conta disso, a vida se apresenta como um conjunto interminável de significantes, cuja compreensão condiciona-se ao grau e à natureza da inserção do indivíduo no contexto posto.

Essa inserção, por sua vez, constitui-se numa espécie de consentimento tácito dado pelo conjunto da sociedade, pautado tanto pelas condições de existência a que fora submetido cada agente na estrutura social quanto pelo tempo de pertença e pelo conjunto de relações práticas estabelecidas por ele com outros participantes do quadro imaginado, representados no tipo e na qualidade das trocas (simbólicas e materiais) realizadas.

Nas sociedades capitalistas modernas, onde as relações sociais pautam-se eminentemente por contrapartidas monetárias, as formas de inserção social são reguladas em função da relação que os indivíduos estabelecem com o mercado de trabalho, locus privilegiado de reconhecimento social. Neste sentido, a operação de políticas sociais que pretendam contribuir para a "emancipação sustentada" de seus beneficiários, como é, por exemplo, o Programa Bolsa Família (BRASIL, 2004a), deve se dar vinculada à dinâmica do mercado de trabalho, e por isso é desejável que o processo de seleção de seus beneficiários, operado através do Cadastro Único, se dê integrado à 
criação de oportunidades para a inclusão produtiva dessas pessoas e, consequentemente, sua autonomização para o exercício da cidadania, dada pela ocupação de uma posição de maior legitimidade social.

Ao tratar do tema da construção da realidade social, Pierre Bourdieu (2004, p. 149) reconhece aí a operação de "estruturas objetivas”, mas observa, ao mesmo tempo, a importância de se considerar também "a percepção dessa realidade, as perspectivas, os pontos de vista que [...] os agentes têm sobre essa realidade". (BOURDIEU, 2004, p. 156-157) Depreende-se daí que as percepções sobre o mundo social são estruturadas tanto objetiva quanto subjetivamente, e encontram-se numa luta simbólica para estabilizar-se, cada uma, como sendo a "visão de mundo legítima" (BOURDIEU, 2004, p. 161), numa tentativa contínua, não necessariamente consciente, de firmar-se, sob a anuência relativa de outras posições. É dessa perspectiva, portanto, que Bourdieu constrói a noção de "espaço social”, tendo o fito justamente de apresentar um esquema lógico de explicação da realidade, compreendida esta como "um conjunto de relações invisíveis [...] que constituem um espaço de posições exteriores umas às outras, definidas umas em relação às outras". (BOURDIEU, 2004, p. 152)

O espaço social constitui-se, então, num espaço relacional, onde cada ponto de vista representa não mais que um "ponto de vista", um parecer emitido a partir de uma localização específica, mas cujo peso na conformação desse espaço se define em relação às demais posições, dadas em função das condições de existência em que os agentes sociais se encontram. Desta forma, a vida em sociedade organiza-se hierarquicamente, fundamentada em determinados princípios distintivos, ou tipos de "capital”, elemento em torno do qual os agentes se reúnem pautados em interesses a ele relacionados, e que são representados majoritariamente pelo capital econômico e pelo capital cultural. A hierarquia das posições sociais se define, assim, tanto em função do volume de capitais apropriado pelos agentes, quanto pelo peso relativo que tem cada tipo de capital no volume global, num processo contínuo de lutas simbólicas estabelecidas entre os agentes sociais para validar as suas posições e seus interesses em relação aos demais. (BOURDIEU, 1996)

Todo tipo de capital guarda em si um certo nível de "capital simbólico", uma característica que dá ao capital reconhecimento social, em função da sua correspondência com as categorias mentais de percepção do mundo. O capital simbólico, segundo Bourdieu (1996, p. 107), “é a forma que todo 
tipo de capital assume quando é percebido através de categorias de percepção, produtos da incorporação das divisões ou das oposições inscritas na estrutura da distribuição desse tipo de capital”. Assim, as posições sociais não são dadas necessária ou imediatamente pela posse ou não de capitais, mas pelo reconhecimento que ele adquire no âmbito do conjunto das relações sociais, pelo significado que os agentes sociais atribuem a essas posições. "Posição social” corresponde a uma classificação, e será mais ou menos legítima de acordo com o reconhecimento dispensado pela sociedade. Ou seja, no caso deste estudo, a posição social dos pobres resulta da forma de identificação, conhecimento e reconhecimento desse estrato de beneficiários incluídos nos PTR ou potencialmente beneficiários dos programas de assistência social.

Seguindo ainda a perspectiva de Bourdieu, sendo as formas de ver o mundo uma construção, as classes dos agentes são, então, construídas, e uma vez que o Estado goza da prerrogativa da classificação social, ele toma para si a tarefa de construção da realidade social. Assim, o Estado encarna o poder legítimo de designar, de atribuir valor; ele tem "poder criador" (BOURDIEU, 1996, p. 114), porque define o estatuto social dos agentes e classes de agentes sociais, seja pela codificação, pela delegação ou pela nomeação.

Por meio dos sistemas de classificação [...] inscritos no direito, dos procedimentos burocráticos, das estruturas escolares e dos rituais sociais, [...] o Estado molda as estruturas mentais e impõe princípios de visão e de divisão comuns. (BOURDIEU, 1996, p. 105)

Essa perspectiva forja a ideia central que norteia este trabalho. Assume-se aqui que a construção de um Cadastro Único, etapa de identificação da população-alvo necessária à implementação dos projetos de assistência, atribui previamente a condição de ser pobre a essa população, o que pode redundar na designação desta condição social às pessoas assim consideradas e impor-lhes uma posição determinada no espaço social, estabelecendo, por conseguinte, as formas e limites de sua atuação no âmbito do trabalho social de construção da realidade. Assim, o processo de classificar e identificar quem é pobre pode reiterar o ordenamento diferencial da sociedade, onde a perenização da condição de pobreza seja legitimada como resultado do poder criador do Estado na implementação de ações de assistência social. 
Para explicar as diferentes formas de visão de mundo e, consequentemente, de construção do mundo social, Bourdieu (2008) recorre ao conceito de habitus: esquemas mentais de percepção e apreciação. Eles se formam pela incorporação das estruturas a que os indivíduos estão sujeitos, dos espaços ocupados, pela posição no espaço social. Convertem-se em sistemas de visão do mundo e de compreensão sobre as suas divisões. É a partir do habitus que os agentes sociais classificam as coisas e os outros agentes no mundo social, suas próprias práticas e as alheias. Classificam e se autoclassificam, portanto. Os julgamentos emitidos pelo habitus convertem as práticas e produtos em um "sistema de sinais distintivos", (BOURDIEU, 2008, p. 163, grifo do autor) Assim, possuir um determinado bem ou agir de determinada maneira expressa uma condição ou um pertencimento social. Logo, o habitus está diretamente relacionado às condições de existência; as práticas a ele associadas exprimem as diferenças objetivamente inscritas no espaço social.

Esse enraizamento das formas de conceber a realidade nas estruturas objetivas de distribuição das coisas e dos agentes no espaço social imprime um matiz de naturalidade a essa realidade, dissimulando as lutas e conflitos subjacentes que se estabelecem para que tal distribuição se dê da forma como se apresenta. As divisões sociais não são uma condição dada, são construídas num processo ininterrupto de lutas, que constitui a dinâmica da vida social, e a posição que os agentes conseguem ocupar lhes confere um certo grau de reconhecimento ante o conjunto da sociedade, define a sua identidade social e, assim, o peso relativo que desempenhará na continuidade das lutas. O "efeito de naturalização" (BOURDIEU, 1997, p. 160) da realidade social representa, portanto, o sucesso de uma forma específica de enxergar essa realidade sobre outras tantas possíveis, forma essa que tem nos instrumentos de classificação operacionalizados pelo Estado, a base para a sua consolidação. As posições sociais têm, portanto, caráter constitutivo sobre a identidade social dos agentes, definida em função das diferenças sociais e representações vigentes. A identidade social conforma, então, a expressão do reconhecimento mútuo das diferenças sociais, a legitimação da importância ou do peso que têm as posições, umas em relação às outras. O ponto de vista de cada agente é, assim, corroborado pelos demais pontos de vista, e isto se dá porque o ponto de vista do Estado "se impõe como ponto de vista universal”. (BOURDIEU, 1996, p. 120) 
Enquanto estrutura organizacional e instância reguladora das práticas, ele [o Estado] exerce permanentemente uma ação formadora de disposições duradouras, através de todos os constrangimentos e disciplinas corporais e mentais que impõe, de maneira uniforme, ao conjunto dos agentes. (BOURDIEU, 1996, p. 116)

Em outras palavras, é necessário ter-se sempre em vista o aspecto circunstancial das posições sociais, sob pena de naturalizá-las, de conceber como imutável uma condição social que, como observa Bourdieu (2008), dá conta de um momento da trajetória social dos agentes. É neste sentido que o autor afirma que os habitus devem ser apreendidos sincrônica e diacronicamente, ou seja, não basta considerar a posição ocupada pelos agentes num determinado momento (sincrônica), mas, sobretudo, a sua trajetória, as eventuais inflexões sofridas em seu curso de vida (diacrônica), que fazem diferir as posições ocupadas naquele momento daquelas projetadas ou apontadas como possíveis em seu ponto de partida na arena das lutas sociais. Logo, a realidade não representa um conjunto de posições estanques objetivadas, compreendidas e resignadamente aceitas pelos agentes sociais. As diferentes posições são definidas umas em relação às outras, num processo de luta por definição. Não conformam uma estrutura perene, mas expressam um momento das lutas sociais aí desenvolvidas. Lutas de classificação, de designação, de atribuição de valor, de significação, enfim. Os capitais mobilizados nessas lutas representam, assim, poderes; são propriedades que não só dão distinção, mas permitem distinguir. A ordem social estabelecida é uma ordem construída em torno de interesses, numa relação contínua de interinfluência entre diferentes atores sociais.

Sob essa ótica, no contexto em que este trabalho foi desenvolvido, observa-se que o agrupamento pretendido pelo Cadastro Único, de toda a população de "baixa renda" - pobre e extremamente pobre -, pode vir a imputar estatuto legal a essa condição e a toda carga de atribuições que dela deriva, gerando um efeito de naturalização. O Cadastro se destina à seleção do público-alvo da assistência social e toma como definição critérios dos programas de assistência e do Bolsa Família; isto demonstra que a medida oficial da assistência considera como critério definidor da pobreza uma concepção de "pobreza absoluta", que diz respeito a um "mínimo vital” necessário à "sobrevivência física” dos indivíduos. (ROCHA, 2003, p. 11) Essa apartação da noção de pobreza da dinâmica do mercado de trabalho dificulta a observação da produção da pobreza enquanto efeito das relações 
contraditórias do próprio mercado de trabalho e da distribuição de renda, ou seja, das relações de desigualdades sociais. Desta forma, cria o risco de se construir uma via específica de "identitarização" desse público e de excluí -lo da arena de lutas que dá forma à realidade social.

Essa discussão evoca uma reflexão acerca da formação de grupos ou classes, por se tratar de um produto das classificações sociais, das lutas de interesses. Quando se designa um grupo, também a sua posição social está sendo designada e, consequentemente, a identidade social de todos os agentes nele compreendidos. As classes de agentes distribuídas objetivamente no espaço social são grupos em potência, estão no campo do possível. A passagem de uma "classe teórica" a uma "classe real" pressupõe o concurso de lutas simbólicas e políticas; um trabalho de mobilização de agentes cujas propriedades objetivas apontem para a possibilidade de aproximação. É indispensável, então, que se evite "transformar em propriedades necessárias e intrínsecas de um grupo qualquer [...] as propriedades que lhes cabem em um momento dado, a partir de sua posição em um espaço social determinado e em uma dada situação de oferta de bens e práticas possíveis". (BOURDIEU, 1996, p. 17-18, grifo do autor)

As condições de existência estabelecem os limites de ação dos agentes nas lutas sociais e, consequentemente, as condições para a reprodução ou alteração da sua posição social. A vivência prolongada de uma posição é o processo pelo qual os agentes internalizam as formas de divisão ou a distribuição de posições do espaço, e isto se tornará o princípio de sua orientação, no sentido de que, pautados nessa forma de perceber o mundo, é que vão classificar as coisas dele; vão atribuir significado às práticas em geral. Esse esquema interpretativo da realidade é que dará lógica aos eventos da vida. A forma de distribuição das propriedades tornar-se-á um esquema de distinção de tal modo arraigado que as distinções parecerão evidentes, como que naturais. Assim, a herança de capitais ou a ausência deles deverá apontar qual o futuro possível para cada agente. E, da mesma forma que as localizações semelhantes geram formas interpretativas semelhantes e daí práticas semelhantes, os destinos dos agentes semelhantes em propriedades tendem a ser também socialmente semelhantes.

Quando se toma a realidade como ordem natural das coisas, e não como um "momento" das lutas sociais, reforça-se a estrutura de distinções, o que se verifica, por exemplo, na estrutura de distribuição dos bens e dos agentes no espaço físico. (BOURDIEU, 1997) Nesse espaço, o que dá 
distinção a uma determinada posição é a sua relação com propriedades tornadas raras e que a opõem a posições onde essas propriedades estão ausentes ou em menor frequência. Essa oposição se manifesta basicamente no distanciamento entre os lugares onde se concentram ou rarificam os bens cobiçados por todos. Assim, o espaço físico apropriado simboliza a apropriação de posições do espaço social e o "retraduz" empiricamente, torna-se a sua manifestação empírica. (BOURDIEU, 1997) As hierarquias simbólicas estão manifestas no espaço físico que lhes dá materialidade, e a forma pela qual são interpretadas lhes atribui o caráter distorcido de natural, um "efeito de naturalização que a inscrição durável das realidades sociais no mundo natural acarreta”. (BOURDIEU, 1997, p. 16o, grifo do autor) A estrutura de distribuição dos agentes no espaço social se retraduz, então, numa realidade social, numa estrutura distributiva de bens e serviços, e mesmo, de oportunidades de apropriação. A posição simbólica encontra correspondente na localização empírica, e as estruturas do espaço social se inscrevem de tal modo no espaço físico que assumem um caráter de imutabilidade.

Mais uma vez, o que de fato constitui esses espaços "reificados" e seus benefícios é a luta estabelecida entre os agentes em seus respectivos campos. Os ganhos que daí se extraem definem ou redefinem a sua localização. Esses "ganhos de localização" são "rendas" de situação, nos diz Bourdieu (1997, p. 163), dadas pela proximidade a "agentes e [...] bens raros e cobiçados"; e "ganhos de posição" ou de classe, ou ainda, de ocupação ou acumulação, conferidos aos agentes em razão de "um endereço prestigioso" ou da posse de um espaço físico que distancia e exclui simultaneamente. O volume de capital possuído e a estrutura desse capital determinam em graus e modos a apropriação dos bens gerados no espaço, bem como o exercício da dominação sobre este. É neste sentido que Bourdieu (1997, p. 164) afirma que "o capital permite manter à distância as pessoas e as coisas indesejáveis", isto porque o volume e a estrutura dos capitais propiciam a monopolização das oportunidades de apropriação, de locomoção etc., da mesma forma que "a falta de capital intensifica a experiência da finitude: ela prende a um lugar”. (BOURDIEU, 1997, p. 164)

Nas lutas sociais, das quais as condições de existência resultam, poucos agentes são exitosos. Não se trata de um fenômeno natural, algo do tipo "sempre foi assim e sempre será", como se pode pensar a respeito da condição de pobreza, mas de um estado, de uma circunstância para a qual concorreram diversos fatores e sobre a qual pesa a insígnia da classificação 
social. Por isso, "a reunião num mesmo lugar de uma população homogênea na despossessão tem também como efeito redobrar a despossessão, principalmente em matéria de cultura e de prática cultural”. (BOURDIEU, 1997, p. 166) Características atribuídas a um indivíduo ou grupo são acompanhadas de permissões ou proibições correspondentes, vantagens ou obrigações. A luta social converte os limites incorporados em fronteiras empíricas. Os capitais são, assim, simultaneamente, caracteres distintivos e armas de luta. São investidos e reinvestidos no processo que pode levar à alteração da ordem, no sentido de alterar as localizações espaciais dos agentes, mantendo, ao fim, a lógica de ordenação. 